\title{
The Research Design of Parenting Education for Future Parents*
}

\author{
Wang Liansen \\ Shandong Women's University, Jinan, China; \\ Shandong University, Jinan, China \\ Ji Yinping \\ Shandong Women’s University, Jinan, China
}

\begin{abstract}
Parenting education can help parents gain experiences of being competent parents and help people who want to be parents get ready to be good parents. The idea of parenting education has been advocated in countries (areas) all over the world for nearly 100 years, and the study of it develops correspondingly accompanying with and leading practice to obtain rich achievements. However, the objects of those practice and study of parenting education mainly are only population who are already or will become parents (parents-to-be in pregnancy). As quasi-occupation, parents just like other occupations should receive pre-service training before becoming parents to possess parental “competence.” Theoretical research and corresponding practice exploration of parenting education should be launched as early as possible for future parents, "potential parents.” The new research clarifying in this article takes Chinese unmarried youth (18-28 years old young people, especially college students) as research subjects. Its outline includes basic problems (what and why), contents (what to teach), channels (who will teach), and ways (how to teach) of parenting education for unmarried youth. Through fully investigating and exploring the necessity, feasibility, particularity, and implementation of parenting education for unmarried youth, and widely proving the scientific rationality of planning contents and forms in parenting education, and testing the willingness of youth to accept parenting education, innovations of research categories, objectives, and achievements as several papers and works can be implemented. Primary opinions about "what," "why,” "what to teach,” "who,” and "how” on parenting education for unmarried youth is put forward.
\end{abstract}

Keywords: parenting education, parent education, parental education, unmarried youth, review

\section{Introduction}

Family is the basic cell of society and the primary environment for children's growth. In the first class for children, parents are the first teachers of them. Therefore, the educational concept and cultivation skills of parents are not only private in the family, but also related to national quality and future. It is necessary to provide various ways for parents to gain such essential education and training what is "parenting education" (also called as "parent education," "parental education," and "father-and-mother education") in the society.

* Acknowledgement: This research was financially supported by Humanities and Social Science Research Project of Ministry of Education (Grant No. 15YJA880069), research project to talent introduced of Shandong Women's University (Grant No. 2016RCYJ16), and Project of National Social Science Foundation of China, and Key Project of Chinese Foundation for Teacher Development of Ministry of Education.

Wang Liansen, Ph.D., professor, School of Education, School of Tourism, Shandong Women's University; Research Center for Higher Education, Shandong University.

Ji Yinping, Ph.D., associate professor, School of Foreign Languages, Shandong Women’s University. 
This kind of education and training can help parents gain experiences of being competent parents and help people who want to be parents get ready to be good parents (Gai, 2006).

\section{Practice and Research of Parenting Education: Review and Prospect}

According to nurture assumption, which emphasizes the important influences of parents on children's growth, and believes the functions of family (parents) will directly affect the growth of children, and education assumption which takes parenthood as profession, and believes parents can only be efficient parents after taking education and training, the idea of parenting education has been advocated in countries (areas) all over the world, especially in western society since 1930s. Parenting education has obtained general concern and prosperous development in different levels of planning, research, legislation, practice, and implementation. In last hundred years, surrounding "How to be good parents," the study of parenting education develops correspondingly accompanying with and leading practice to obtain rich achievements (Leibowitz, 1977; Blau, 1990; Cataldo, 1991; Bornstein, 1995; Carter, 1996; Simpson, 1997; Lamb, 1997; Yoshinaga, 1999; Peña, 2000; Hammer, 2001; Bornstein, 2002; Ministry of Education of Japan, 2003a, 2003b; Desforges, 2003; Anderson, 2007; Guryan, 2008; Lee, 2009; Martínez, 2009; U.S. Department of Education, 2010; Rodrigo, 2015; Asano, 2016; Ceka, 2016).

In China mainland, parenting education marked with the establishment of parent school was originated at the beginning of 1980s. At the end of 1980s and the beginning of 1990s, governments started to pay attention to the guidance of family education for parents and made plans and arrangements. At present, the coverage of family education services and guidance institutes in all levels expands gradually. Similar with foreign research, domestic research on parenting education also develops successively with practice. Study on parenting education occurs in the study on family education at the beginning. In 1980s, the study on family education recovered and developed after reform and opening-up of China. A large amount of research papers, report publications, and works are published every year (Luo, 2005), including some studies on nearly parenting education, such as "education ideas of parent” (Yu, 1995; Sun, 2003) and "parent quality” (Guan, 1998; Zhang, 2007). Before and after the 20th century, professional studies on parenting education occur. Although parenting education still belongs to the large category of family education, it starts to appear with independent face of family education guidance until today (H. Li, 1998; S. Li, 1999; H. Li, 2000, 2004; Shen, 2004; Y. Li, 2012; China Center for Children, 2016). Then, research results of "parent education" (Yue, 2004; J. Li, 2008), especially parenting education (H. Liu, 2009; H. Li, 2010, 2015; Z. Li, 2010; Fan, 2013; Xu, 2016) are presented. All of these studies promote parenting education develop from scientization and socialization to professionalization, institutionalization, and systematization, and from simple skill training to all-round development, and from remedial and corrective training to preventive and developing training. With category expanding, parenting education starts to pay attention to "developing family life education" for the establishment of family development ability (Yang, 2016).

In recent 100 years, especially recent 40 years of China, the foreign and domestic practice and study of parenting education has had its concerning category expanding, but its research and guidance objects are still population who are already or will become parents (parents-to-be in pregnancy).

At present, the role of parents as management and teacher becomes an essential professional occupations, father, and mother in the family as the principle bearers in family operating hub, especially family education. As quasi-occupation, parents just like other occupations should receive pre-service training before becoming 
parents (as potential parents) to possess parental competence. Therefore, they can better perform the responsibilities of parents and the role of management. In the reality, a large amount of irreversible and irretrievable problems of family education, family dissension, and unhealthy family tradition also show the severe lack in parent competence. Therefore, theoretical research and corresponding practice exploration of parenting education should be launched as early as possible for future parents, "potential parents."

The parenting education research for future parents is an exploring, prospective, and exploited research, because it extends the objects of parenting education from population of parents (mainly parents of children in 0-18 years old) to unmarried youth (potential parents). The addition of pre-service education to existing parenting education (mainly occupational training for newly married couples and pregnant women and on-job training for parents) will make theoretical contribution to the creation of complete chain of pre-service-occupation-on-job in parenting education and its integration. This research will inspire, guide, and help a large amount of unmarried youth establish the opinions of family orientation and moral character cultivation and family affair management. By understanding and grasping basic knowledge and skills of pregnancy, birth, feeding, education, and teaching, these youth can give better education for their children and establish better family with good physical properties, ideas (especially values), and connotations in the future.

\section{Research Contents of Parenting Education for Unmarried Youth}

This research takes Chinese unmarried youth (18-28 years old young people, especially college students) as research subjects to study parenting education in China.

\section{The General Outline}

Basic problems of parenting education for unmarried youth-“What" and "why."

1. Parenting connotation in new age (according to the spirit in General Secretary Xi Jinping's speech (2015) that "pay attention to family, family education, and family tradition");

2. Characteristics and status of unmarried youth (pay attention to their physical and psychological conditions, also ideas, wishes, and demands about love relationship, marriage, and family);

3. Character of parenting education for unmarried youth (emphasize the reserve ability in qualification and optional in conditions);

4. Purpose of parenting education for unmarried youth (point to family construction including family education);

5. Significance of parenting education for unmarried youth (in level of national development, national advancement, and social harmony);

6. Characteristics of parenting education for unmarried youth (compare with the existing parenting education for parents);

7. Principles of parenting education for unmarried youth (explore deeply and follow its intrinsic regulation).

Contents of parenting education for unmarried youth—“What to teach."

1. General contents of parenting education for unmarried youth (pay equal attention to four kinds of education including moral, intellectual, sports, aesthetic, and combine respect with inspiration);

2. Contents of parenting education for unmarried women youth (pay attention to differences: physiological gender and social gender); 
3. Contents of parenting education for unmarried men youth (pay attention to differences: physiological gender and social gender).

Channels of parenting education for unmarried youth (carriers and supporters) — "Who will teach."

1. General channels of parenting education for unmarried youth (consider availability, convenience, and benefits);

2. Channels of parenting education for college students (make refined plans according to group characteristics);

3. Channels of parenting education for urban youth (make refined plans according to group characteristics);

4. Channels of parenting education for rural youth (make refined plans according to group characteristics).

Ways of parenting education for unmarried youth (patterns and methods)—-How to teach.”

1. General ways of parenting education (consider acceptable, scientific, and beneficial);

2. Ways of parenting education for college students (make refined designs according to group characteristics);

3. Ways of parenting education for urban youth (make refined designs according to group characteristics);

4. Ways of parenting education for rural youth (make refined designs according to group characteristics).

\section{Research Objectives}

Basing on sufficient investigation and vigorous tests, requirements of "paying attention to family, family education, and family tradition" should be combined to educate future good parents and construct future good families according to the characteristics and status of unmarried youth. Theoretical framework (basic research) of parenting education for unmarried youth is scientifically constructed to design operating manual (application research) for parenting education with the complete system and strong operability for different population groups (college girls, college boys, urban women, urban men, rural women, and rural men), by applying the theories and approaches of sociology, pedagogy, psychology, physiology, ecology, culture, anthropology, ethics, etc..

\section{Key Points and Difficulties}

The key point of this research is to establish specific contents of parenting education for unmarried youth, basing on interpretation to basic problems of parenting education for unmarried youth (connotation of parenting in new period, and nature, purpose, value, characteristics, and principles of parenting education for unmarried youth). The difficulties lie in the contents of parenting education for unmarried youth, which should not only respect and follow the life values, wishes, and demands of youth, but also inspire and guide youth by combining traditional culture with modern ideas.

\section{Research Ideas of Parenting Education for Unmarried Youth}

\section{Research Procedures}

Step 1: Fully investigating the necessity and feasibility of parenting education for unmarried youth in current times.

Step 2: Deeply exploring the particularity and implementation of parenting education for unmarried youth.

Step 3: Widely proving the scientific rationality of planning contents and forms in parenting education and test the willingness of youth to accept parenting education by consultation, trial teaching, tests, experiment pilots, etc.. 


\section{Research Strategies}

Value-leading. In research direction and guiding ideology, requirements of "paying attention to family construction with family, family education and family tradition” proposed by General Secretary Xi Jinping (2015) must be followed. Then, guiding spirits of "promoting traditional family virtues of Chinese nation, improving family harmony, facilitating the intimate relationship among families, accelerating the health growth of the next generation, and supporting elder people in proper care" should be emphasized and implemented.

Demand-orientation. Guided by values, suitable and acceptable parenting education should be developed to promote knowledge internalization and self-education through completely exploring and following actual demands of youth.

Systematic thinking. Family should be treated as the special ecosystem composed of essential elements, including parents, children, other family members, materials, and cultural environment. Family relations in various aspects, especially interpersonal communication and semiotic interaction between parents and children and couples should be focused, caring about the development of children and parents themselves and the dynamic balance and harmony in development of other family members.

Gender perspective. Face the differences between male and female and determine the contents of parenting education respectively according to physical gender and social gender for male youth and female youth. Moreover, possible differences in channels and forms of parenting education should also be noticed.

Points promote entirety. When the contents of parenting education has been basically completed, trial teaching (from the single lecture to series of lectures, finally to selective courses) will be conducted to relatively centralized and large amount of college students (especially college girls) in colleges and universities of this research groups. After the examination is mature, the program can be propagandized and spread to surrounding colleges and universities. Meanwhile, trial teaching can be conducted in several districts and counties of this city and then promoted to more areas.

\section{Research Methods}

Literature research method. Widely and deeply collecting, sorting, and analyzing foreign and domestic relevant references to extract utilizable and referable information.

Investigation research method. Verifying the necessity of parenting education and exploring the actual demands on parenting education by individual deep interviews, subject group interview, and questionnaire survey (combination of structuring and opening) for youth.

Comparison research method. Comparing "parenting education for unmarried youth in China Mainland" with foreign parenting education (especially that in America, Japan, Taiwan, etc.), existing parenting education/parent education and pre-job/pre-employment training of other industry for reference and development.

\section{Research Innovations of Parenting Education for Unmarried Youth}

\section{Innovations of Research Categories}

Subjects of parenting education extend from family group to unmarried youth.

Previous research and practice of parenting education in China and foreign countries mainly focus on married population, especially those as parents. The parenting education as tutor for them belongs to orientation training and on-job training. This research aims at developing reserve parenting education for would-be parents, belonging to pre-job training. 


\section{Innovations of Research Objectives}

The purpose of parenting education is improved from family education to family construction.

As "family is the smallest unit in a country, while country is composed of thousands of families," Xi Jinping (2015) emphasized that "family construction should be emphasized, paying attention to family, family education, and family tradition" and "to promote family harmony, intimate relationships between families, healthy growth of next generations, and care about elder people. Therefore, thousands of families can become the important foundations for country development, national progress, and social harmony." Family construction which contains family education is the primary responsibility for every family member, especially parents who are the connecting link between the elders and children. The previous research and practice on parenting education focus on how to help parents improve family education. However, this research aims at guiding young people to get the awareness of family foundation, and to reserve ability to construct happy family in the future, not only educating children well, but also establishing a good family.

\section{Expected Research Achievements of Parenting Education for Unmarried Youth}

\section{Forms of Achievements}

Papers. From the preparation, designing and starting to real launching and final conclusion of this project, several (six to eight) high-level original research papers can be completed, containing the following contents: connotation of parenting in the new period; nature, purpose, value, characteristics, principles, and contents (summary for male and female) of parenting education for unmarried youth; and channels and forms of parenting education for college students, urban youth, and rural youth.

Works. By wide and deep investigation, test, and research, experts consultations and market tests in the last stage, "offprint” (Future Good Mother and Future Good Father) or "one-volume” (Future Good Parents) will be completed, with specific content of "parenting education for unmarried youth" as the core, aiming to launch, guide, and help unmarried youth to consider and design how to establish a good family and become the good mother or father in the future.

\section{Usage of Achievements}

Papers will be published in sociology and pedagogy journals for the reference of theoretical scholars and practical workers who are in the fields of youth development, family construction, parent education, and family education guidance. The final paper collection will be formed and sent to various levels of departments of education, women's association, communist youth leagues, civil administration, and hygiene and family planning population by mail or e-mail for reference in relevant decisions and work.

Works will be used as textbooks for college students' parenting education. Moreover, these works can be used as materials in parenting education for unmarried youth organized by all levels of departments in education, women's federation, communist youth league, civil administration, and hygiene and textbooks for self-learning of unmarried youth or newly-married couples and parents by wide circulation through publishing channels.

\section{Primary Opinions on Parenting Education for Unmarried Youth}

\section{"What"}

Parenting education for unmarried youth is actually future parent's education. Its essence is to reserve parenting education which can make preparation for the good mother and father from the aspects of willingness, 
qualification, condition, and capability in the future. Different from previous research on parent education which is the tutorship parenting education aiming at improving the efficiency of parents (especially the ability of child rearing), this kind of education has the function of orientating, modeling, and founding for future good parents and families.

\section{"Why"}

In the view of pedagogy, education as the preparation of life should be earlier, rather than later. Considering the irreversibility of children growth, it is difficult to correct the mistakes of education. Therefore, parents should receive parenting education as early as possible to acquire the education qualification as the first teacher of children. The earliness of parenting education ensures longer learning time and stable learning pace, as well as good learning conditions for college students. In the view of psychology, it requires a long time to develop good values, ideas, sentiments, qualities, and other basic qualities for the parents who are the first teachers of children, and the earlier education, the better foundation. In the view of physiology, children's growth requires good physical health, which is greatly limited to parents' fitness, while the exercise and maintenance of health must be completed in the key period. Therefore, parenting education-containing physics should also be earlier, rather than later. In the view of sociology, the responsibility of mothers or fathers also needs "social support," mainly referring to the support from spouse and his or her family. The support efforts, especially compatibilities are the significant influence factors for parents' responsibilities. Who would be spouse is an option for unmarried young people, and parenting education can teach them how to choose.

\section{"What to Teach"}

Complete parenting education for unmarried youth should include moral education (guidance for world view, values, life view, and values of love relationship, family, and marriage, etc.), intellectual education (learning of knowledge and skills of "love relationship, marriage, pregnancy, birth, nursing, education, and teaching,” etc.), physical education (physical exercise and maintenance, etc.), and aesthetic education (temperament, accomplishment, etc.) and pay attention to the fundamentality and common knowledge of contents. Education contents should be designed from the aspects of idea establishment, qualification preparation, conditional creation, capability improvement, and plan arrangement to make sure the pre-job training completeness and systematic.

\section{"Who" and "How"}

According to characteristics of various kinds of youth, education can be individualized, through the existing channels, such as schools (especially colleges and universities), communities, institutions, medias, etc. or other new special channels, and the ways of lectures, courses, advertisements, activities, consultations, etc..

\section{Conclusion}

In the view of pedagogy, psychology, physiology, and sociology, as quasi-occupation, parents just like other occupations should receive pre-service training to possess parental competence. Theoretical research and corresponding practice exploration of parenting education should be launched as early as possible for future parents. Parenting education for unmarried youth can make preparation for the good mother or father from the aspects of willingness, qualification, condition, and capability in the future. Through the research of parenting education for unmarried youth, theoretical framework of parenting education for unmarried youth would be scientifically constructed and operating manual for parenting education with the complete system and strong 
operability for different population groups (college girls, college boys, urban women, urban men, rural women, and rural men) would be designed, by applying the theories and approaches of sociology, pedagogy, psychology, physiology, ecology, culture, anthropology, ethics, etc..

\section{References}

Anderson K. J., \& Minke K. M. (2007). Parent involvement in education: Toward an understanding of parents’ decision making. Journal of Educational Research, 100(5), 311-323.

Asano, T. (2016). Statements for mothers regarding education in magazine for preschool teachers in the early 1940s: On the series of articles entitled "gekkan youji-no haha" in monthly magazine Youji-no Kyoiku. The Journal of Chubu Gakuin University and Chubu Gakuin College, 17(3), 29-40. (in Japanese)

Blau, Francine, D., Adam, J., \& Grossberg. (1990). Maternal labor supply and children's cognitive development. The Review of Economics and Statistics, 74(3), 474-481.

Bornstein, M. (Ed.). (1995). Handbook of parenting. Mahwah: N.J.: Lawrence Erlbaum.

Bornstein, M. (Ed.). (2002). Handbook of parenting: Biology and ecology of parenting. Mahwah, N.J.: Lawrence Erlbaum.

Carter, N. (1996). See how we grow: A report on the status of parent education in the U.S., Philadelphia. Pennsylvania: Pew Charitable Trust.

Cataldo, C. (1991). Learn to be parents: concepts and contents for the design of programs of formation of parents, Madrid: Visor. (in Spain)

Ceka, A., \& Rabije, M. (2016). The role of parents in the education of children. Journal of Education and Practice, 7(5), 61-64.

China Center for Children. (2016). Research on China family education guidance service system construction and promoting strategy. Beijing: Renmin University of China Press. (in Chinese)

Desforges, C., \& Abouchaar, A. (2003). The impact of parental involvement, parental support, and family education on pupil achievement and adjustment: A literature review. London: Department for Education and Skills.

Fan, C. H., \& Peng, S. F. (2013). The present development situation and future orientation of modern parent education: Social work intervention. Social Welfare, 12, 52-57. (in Chinese)

Gai, X. S., \& Wang, H. Y. (2006). Parent education: Current status and developing strategies. Journal of Northeast Normal University (Philosophy and Social Sciences), 6, 154-158. (in Chinese)

Guan, Y. (1998). Parents' education quality and its instruction: Thinking from investigation of the personality of the one-child group. Journal of Tianjin Normal University, 5, 37-39. (in Chinese)

Guryan, J., Erik, H., \& Melissa, K. (2008). Parental education and parental time with children. Journal of Economic Perspectives, 22(3), 23-46.

Hammer, T. J., \& Turner, P. H. (2001). Parenting in contemporary society. New Nork, N.Y.: Allyn \& Bacon.

Lamb, M. (Ed.). (1997). The role of father in child development (3rd ed.). New York, N.Y.: Wiley.

Lee, E. L. (2009). Using parent-child interaction therapy to develop a pre-parent education module (A Dissertation, the Graduate Faculty of Auburn University).

Leibowitz, A. (1977). Parental inputs and children’s achievement. Journal of Human Resources, 12(2), 243-251.

Li, Y., \& Ren, J. T. (2012). Current status and the development on the supporting system of family education guidance and service in China. Adult Education, 11, 54-57. (in Chinese)

Li, H. Z. (1998). How to make experiment of guidance to children's family education. Studies in Preschool Education, 2, 30-34. (in Chinese)

Li, S. L. (1999). The trajectory and prospect of the children's family education guidance form in Shanghai. Studies in Preschool Education, 6, 11-15. (in Chinese)

Li, H. Z. (2000). The object, content, and form of family education guidance work. Journal of Shanghai Educational Research, 150(6), 35-39. (in Chinese)

Li, H. Z. (2004). The instruction and research of China preschool family education in recent years. Studies in Preschool Education, 6, 10-13. (in Chinese)

Li, J. (2008). The research of the parents' education training: From the family education to the parents' education. Adult Education, 10, 4-6. (in Chinese)

Liu, H. L. (2009). On professional technology about parent counseling. Education for Chinese After-School, 8, 555-556. (in Chinese) 
Liu, H. L. (2010). Parent counseling in social work perspective. Journal of East China University of Science and Technology (Social Science Edition), 6, 16-20, 28. (in Chinese)

Liu, Z. J. (2010). Study on parent education in colleges and universities. Education Review, 5, 37-39. (in Chinese)

Liu, Z. J. (2015). On parent education and universities transformation and development. Journal of Leshan Normal University, 30(6), 100-103. (in Chinese)

Luo, F. (2005). A summary of the progress of family education research in china since 1990s. Theory and Practice of Education, 25(5), 51-55 (in Chinese).

Martínez, R. (2009). Program guide for the development of emotional, educational, and parental competences. Spain: Scretaría General Técnica. (in Spain)

Ministry of Education of Japan. (2003a). Parent handbook (MIE Province version). (in Japanese)

Ministry of Education of Japan. (2003b). Parent note (MIE Province Version). (in Japanese)

Peña, D. C. (2000). Parent involvement: Influencing factors and implications. Journal of Educational Research, 94(1), 42-54.

Rodrigo, M. (2015). Practical handbook of positive parenting. Madrid: Editorial Synthesis. (in Spain)

Simpson, A. R. (1997). The role of the mass media in parent education. Boston: Harvard, Center for Health Communication.

Shen, J. P., \& Han, S. P. (2004). Study on the school's guidance model of modern family education. Journal of Shanghai Educational Research, 3, 60-61. (in Chinese)

Sun, Y. G. (2003). Setting up correct concept of family education and family education in social change. Modern Education Science, 6, 42-44. (in Chinese)

U.S. Department of Education. (2010). Parent power: Build the bridge to success.

Xu, L. Y., \& Zhou, N. L. (2016). On the present status and needs for parent education of preschool children in China. Studies in Early Childhood Education, 255(3), 57-66. (in Chinese)

Yang, Q. G., \& Cao, Y. B. (2016). The professional development path of Taiwan family life education and its enlightenment. Journal of Exploration, 4, 139-144. (in Chinese)

Yoshinaga, N. (1999). Motherhood education in childcare work in early 20th Century: A case study of the child care association of Tottorikami village in Okayama. Japan Society for the Historical Studies of Education, 42(10), 61-79. (in Japanese)

Yu, G. L., \& Xin, T. (1995). Research on educational concept of parents under perspective of social cognition. Journal of East China Normal University (Educational Sciences), 3, 87-93. (in Chinese)

Yue, Y. P. (2004). Enlightenment from parent education qualifications. Studies in Preschool Education, 10, $51-52$ (in Chinese).

Zhang, Q. S. (2007). A probe into parents' educational quality and its cultivation in the new century. Journal of Minjiang University, 3, 135-140. (in Chinese) 